\title{
Theoretical Analysis of Financial Portfolio Model
}

\section{Xingang Wang}

Graduate School of Northeast Forestry University.

Email:920028102@qq.com

Received June, 2013

\begin{abstract}
This article introduces portfolio selection model proposed by Markowitz in 1952, as well as research of model promoted continually by subsequent researchers, and then introduces a more classic pricing model CAPM in stock market, and discusses difficulties in the study of modern portfolio theory, and forecasts problems of benefits and risks.
\end{abstract}

Keywords: Portfolio; CAPM; Benefits and Risks

\section{Portfolio Selection Model}

Portfolio (portfolio) refers to that different investor assets are grouped together by a certain percentage as an investment, and stocks, bonds, discharge capacity, collectibles, and other objects can be part of portfolio as an investment. Portfolio Theory discusses the interrelation between each asset and other assets of risk and return, and how investors choose their optimal portfolio reasonable and other issues.

1) Standard portfolio model

Before H. Markowitz founded the modern theory of portfolio, Western financial asset investment theory has experienced more than a century. After World War II, Western nations suffered rapid economic recovery and investment activities of financial assets also would be booming. In the context of this reality, Markowitz founded portfolio selection theory. Markowitz used matrix algebra, vector spaces, probability and statistics and other mathematical methods, to do qualitative and quantitative analysis of portfolio selection theory in portfolio investment.

Portfolio is an effective way to diversify investment risks. In 1952 Markowitz published a classic paper Portfolio Selection, and laid the basis for Portfolio theory, and thus won the Nobel Prize in economics. Purpose of portfolio selection model proposed by Markowitz is to diversify investment risks essentially under the premise of maximizing without loss of yield. He pointed out that the risk of the portfolio not only depends on features of individual securities, [1]but also on correlation between securities in the securities portfolio. Generally speaking, the lower the correlation between securities is; the lower the portfolio's risk is.

In Markowitz's theory, the Evaluation indexes of Risk
Securitization are thus two, named investment average yield $\mu$ and yield variance $\sigma^{2}, \mu$ are the Evaluation indexes of the securities profitable size, and $\sigma^{2}$ are securities risk indicators. Investors can use the following models to determine the optimal portfolio.

Optimal portfolio can be determined by the following model

Model A

Min $a^{a}=x^{2} \Omega x$

$x^{2}-\mu=\mu^{\circ}$

$x^{2}-\mathrm{e}=1$

Where $X$ is the variance of securities investment rate of return, $n$ securities investment ratio vector is $X$, the covariance matrix $X$ is $n$ kind of stock returns, $X$ is $n$ kind of bond yields mean vector, $X$ elements for 1 n-dimensional vector, for the portfolio expected rate of return.

Model A fails to consider the negative investment proportional coefficient, due to the negative investment ratio means selling the relevant securities, and short selling in some occasions, especially in difficult to realize our country, so it is necessary to consider the case of no short sale.

Model B

Min $a^{2}=X^{2} \Omega X$

$X^{1}-\mu=\mu$

$X^{1}$-en $=1$

$X>0$

Model A and model B are allowing short-selling or not under the conditions of the Makovecz mean ---- variance model. Their meaning is: In the given securities investment is expected to yield under $X$ conditions, the securities portfolio investment risk. Based on the $X$ positive definite, [2] and its corresponding organization investment risk optimal model of A solution. 
At present there is no analytical model of $\mathrm{B}$, but the domestic and foreign experts have proposed some algorithm, tree algorithm to improve the solution model of B optimal solutions are given. The optimal model $\mathrm{A}$ and model B solutions usually can be used as an effective portfolio. But because the expected variance models especially the computational complexity of model B, so far in solving large-scale investment securities organizations are still restricted. Some scholars in order to solve this problem using a similar linear programming technique or index model to reduce the parameters to be estimated. Also some scholars use the income difference, deviation as a measure of risk, in order to simplify the calculation.

Below is a brief introduction of several other models

1) Max Standard Analysis

Due to the law and policies, there are some proportions or limitation in total amount for securities groups in single or all securities investments. If such limitation differs to every security, then the following constraint sets are listed:

$$
\left\{\begin{array}{l}
n \\
\Sigma X i=1 \\
t=1 \\
X t \geqq 0, \mathrm{i}=1, \ldots, n \\
X t \leqq U i, \mathrm{i}=1, \ldots, n
\end{array}\right.
$$

All these constraint sets above are the same as that of standard portfolio selection mode except the max investment number $U i$ (it is assumed as a constant) of each securities. The max standard analysis is an exception of portfolio selection mode.

2) Tobin-Sharp-Lintner Model

Tobin-Sharp-Lintner Mode allows to considering the other flow direction of capitals. However, there is a premise that is the flowing out amount of money can not overpass its own amount but the flowing in money has no limitation. Therefore, portfolio selection is restricted by the following items:

$$
\left\{\begin{array}{l}
n \\
\Sigma X i=1+X n+1 \\
i=1 \\
X i \geqq 0, \mathrm{i}=11, \ldots n \\
X n+1 \geqq-1 \\
\quad \text { or it can be written as } \\
n \quad \Sigma X i-X n+1=1 \\
i-1
\end{array}\right.
$$

Here it should be noticed that the limitation of $X n+1$ is not 0 but -1 . In the analysis of Tobin (1958), Sharp (1964) and Lintner (1965), the variable $X n+1$ represents borrowing if it is a positive number and loan if it's a negative number. As for the variance $V n+1=\sigma n+1$, if $n+1$ is 0 , then $i=1, \ldots, n, \sigma n+1$ equals 0 as well. Usually, the rate that a investor get form the loan and borrowing refers to the risk-free rate. It can be expressed as $\gamma 0$. Since $X n+1$ means the borrowing money, $\mu n+1=-\gamma 0$.

3) Model for Bear Position That Need Attachment Mortgage

If the variable has no non-negative limitation, i.e, only under the condition of $\Sigma X i=1$, the following feasible solutions may appear:

$$
\left\{\begin{array}{l}
X 1=-1000 \\
X 2=+1001 \\
X \mathbf{1}=0 i=3, \ldots, n
\end{array}\right.
$$

The answers above mean the 1000 unit bear of securities 1 and the 1001 unit bull of securities 2 . In fact, it is impracticable for individual, investment institution or brokerage. According to the law, mortgage is a must. Thus, the constrained items can be showed in the following ways:

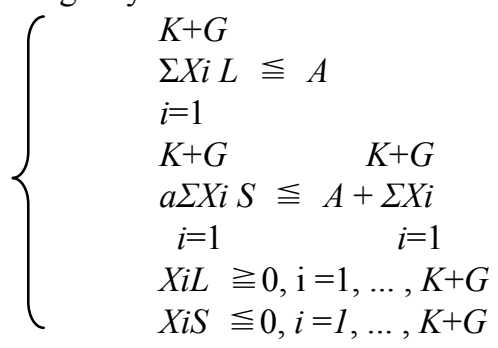

A here means assets; XiL means the bull position of securities $i$; XiS means bear position of securities $i$. The money that total number multiplies $a$ which means the require of mortgage should not surpass the money that right capital surpluses the bear value which can't be used as mortgage, i.e the Securities $K$.

\section{Capital Assets Pricing Model}

Capital Assets Pricing Model, short for CAPM, is found and raised single and respectively by William F. Sharpe, an American economist who won the Nobel Economics Prize in 1990, John Linter and Jack Treynor. This model is at the core of capital market theories and it's a significant achievement of modern financial theories and securities theories. This model attaches great importance to guiding the securities investment.

1) Assumptions of CAPM

CAPM is developed from the portfolio selection and the assumptions about which are more rigorous than capital group theories. The basic assumptions are listed as follows:

a) All investors are risk aversion. They weight the gains or risks or assets with the expected value or variance or standard deviation of the asset returns.

b) Investors determine the investment based on the single gains and risks and the investment horizon are the same.

c) There's no obstacle in securities market, which means the transacting fees are zero. The transacting amount of assets is divisible. Investors can buy any asset 
in market price according to his economic ability.

d) The judgment of investors to the insurance of asset gains is the same.

e) All investors could borrow or lend unlimited funds be issued at the risk free rate and borrowing and lending rates are the same.

f) Tax will not influence securities transactions and asset selection and there not any kinds of market imperfections.

g) All investors can only buy or sell assets at the market price (price taker).

Under these assumptions, the first three and the last one are relatively realistic. First, the vast majority of investors are risk averse, and they mostly estimate investment income and risk in accordance with the expected benefits and possible volatility. Second, though the single-period revenue assumptions seeming simple, as the future of income can be considered from the asset prices of the end period, and the asset price difference between ending and beginning of the period will be reflected as current benefits and risks. Therefore, the second assumption is not difficult to accept.

Third, in the developed securities market, the transaction costs, which are relatively low, will not have much impact on the asset transaction, and most investors are price takers. Assumptions d), e), f) are different from the actual situation. For example, consistency expectation is impossible, and actually quite complex tax system is very complex, which will certainly be an impact on securities transactions and selection of investors. There must be difference in interest rates when borrowing and lending money, it is impossible to borrow and lend money unlimitedly. But it is necessary for the capital asset pricing model to propose these assumptions, and in turn, the capital asset pricing model is useful for securities investment. The impact of deviation between assumptions can be further discussed.

2) Capital and Asset Pricing Model

The applications of Markowitz's decentralization thought in the asset allocation management require a lot of computing. Sharp think we can use a simplified method to achieve the same effect. The method he proposed requires the investor to know relationship between each stock's annual earnings and annual earnings of the market, which can be used to represent by share price index.

Investment risk can be classified into two categories, systematic risk and unsystematic risk. If you use ratio of covariance COVjm of an asset (assuming the asset $j$ ) and the market portfolio and the market portfolio variance $\sigma^{2}$ $\mathrm{M}, \mathrm{COVJM} / \sigma^{2} \mathrm{M}=\beta j$ as its systematic risk measure of the strength, the relationship between an asset J's revenue expectations and the whole system air can be represented as follows:
$E(R j)=$ Expected return of assets $J$

$\mathrm{R} f=$ Benefits of risk-free assets

$\mathrm{E}(\mathrm{RM})=$ Expected return of market portfolio

$\beta j=$ coefficient $\beta$ of asset $j$

The above formula is capital asset pricing model (CAPM), which reflects relationship between risks and return of each asset.

3) The Features of Capital Asset Pricing Model

CAPM has following two significant properties

(1) under the balanced situation the relationship between the returns from assets and the risk have everything to do with the SML(Security Market Line).High risk high returns, vice verse. The relationship between $\mathrm{E}(\mathrm{R})$ and $\beta$ is the straight line up from left to right. As shown:

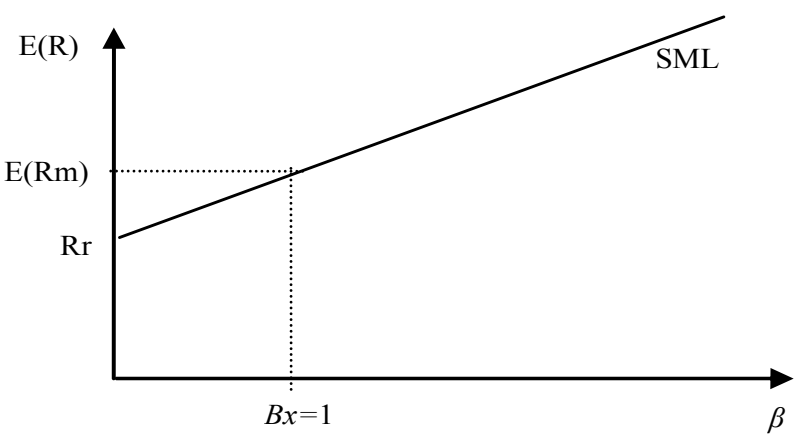

(2)The $\beta$ in the Asset Portfolio is the component of $\beta$ 's weight-sum in the asset of this group. For instance, the investors invest the capital $\mathrm{x}$ with ratio $a$ in $\beta x$, invest the capital $\mathrm{y}$ with ratio $\mathrm{b}$ in $\beta y$, so the $\beta$ in Asset Portfolio $a x+b y$ can be shown as:

$$
\beta p=a \beta x+b \beta y
$$

This important property shows that CAPM is true for any Asset Portfolio.

4) Determination of $\beta$

We utilize the CAPM's relation between its earning and the risk in the process of the portfolio investment in order to guide the option of the securities, and to estimate the relevant security $\beta$ is the key of the application of the CAPM.

The estimate of the $\beta$ used to adopt the Linear Regression and some historical data. Generally, the adopted Linear Regression Model is:

$\mathrm{Rj}=\mathrm{aj}+\beta j R m t+e j t$

aj refers to the intercept term from the regression equation

$\beta j$ refers to the estimated value of $\beta$, the slope in the regression equation

$R m t$ refers to the portfolio of the market

$R j t$ refers to the return of the asset $\mathrm{j}$

Ejt refers to the random error

$R m t$ and Rjt are the historical data, $a j$ and $\beta j$ can be gotten from the regression estimation. 


\section{The Issues about the Gain and Forecast in Security Portfolio Theory}

Among the various kinds of theories about the option of Security Portfolio the further gain and variance are the basis of the decision. And it's a difficult point of the present study that how to forecast the security portfolio. As the security portfolio is a random variable so it's will not just a simple repetition. The historical data is insufficient for some investment projects or assets, especially emerging industries which because of the changes of the economic development, policies and etc. So the forecast by the historical data like 'driving by the rear-vision mirror', [3] so the effect is unsatisfactory phenomenon. There is no investor can forecast the further gain of the securities precisely, from this point, there are two Bayesian methods which suitable to the analysis of the securities of the financial market: fundamental analysis and technical analysis

1) Fundamental analysis

Fundamental analysis, is the analysis and study of the securities, especially the stock, and put priority in the intrinsic value of the securities. By analysis the macroinvestmental environment, especially the basic case of economic environment, the publisher's industry, to seek the value of the securities and decide whether it's worthy to be invested.

The change of the securities' price can be caused by several reasons. In political, the war the political turmoil the leadership change and so on, will affect the investor's confidence more or less and then affect the stock market; in economic aspect, the economic growth the inflation the change of the interest rate the exchange rate all of them will have an effect on the stock market.

National policies such as control the money supply, adjustment of tax, rate of tax, to support, lean or restrict to an industry and etc, all will affect the stock price. So keep a close eye on the change of the macro-politics and economy is very important for the analysis and study.

Industry analysis refers to analyzing the issuer and the listing Corporation out of what kind of industry and the company is in the status of the industry. The company position in the industry is also very important, in different position in the same industry, its ability to grow different. The company's high status, high visibility, easy to obtain the stable and huge profits, but its growth ability may be weak. The position of the lower company, visibility is not high; the lack of competitiveness, but future growth capacity may be strong. Growth firms are a better choice for investors.

Analysis of the company itself is the most important part of the basic analysis. [4]To include many aspects analysis company, such as the products of the company, in what the product cycle, market share, new product development ability. The key to the analysis of the com- pany's marketing efficiency, production efficiency and management efficiency. Through the analysis of financial indicators, such as the balance sheet, income statement, marketing situation analysis of the company's, the company also analysis of stability, activity ability, profit ability, growth ability through the company's other indicators.

In short, the basic analysis method is refers to the use of statistical data, using a variety of economic indicators, the proportion, method of dynamic analysis, from the macro political, economic, to the industry analysis, until the business profit status and Prospect of micro analysis, evaluation of enterprises issued by the securities, and as far as possible to predict its future change, as investors investment basis.

2) Technical analysis

Technical analysis is based on the statistical data of the future past stock market movements. [5]Technical analysis is purely focused on the analysis of price and the quantity of securities, without considering the company's financial position and profitability. According to the price and trading volume change, to predict the stock price up or down, to determine the behavior of investment. This method considers all affect securities, especially various kinds of factors of stock, will be reflected in the price level and stock trading volume. If the phenomenon of certain activities, the market price changes, including the cycle has appeared in the past, is very likely to appear again in the future. History will repeat itself.

Technical analysis method mainly through statistical quantity price and trading of securities. This analysis method is developed to today, can be said to be rich and colorful, perfection. Such as Dow Theory, the moving average line, $\mathrm{K}$ line graph, chart, and bar chart.

Fundamental analysis and technical analysis have strengths; they analyze the stock market from a different perspective, reflecting the change of the stock market to a certain extent. Difference between fundamental analysis and technical analysis: the former is mainly to look forward, pay attention to the future earnings and risk; the latter mainly look back, to the market already happening to predict future basis. In practical analysis, should be to combine the two organic.

Through the analysis of the previous price data, [6]the future trend can be predicted. However, the basic analysis for the importance of stock prediction can not be ignored. Therefore, the Bayesian method is proposed in this paper, which embodies the idea: according to the latest news, including the expert experience and subjective judgment, revised historical data model.

Through the analysis of the previous price data, we can predict the future trend. However, the importance of basic analysis for the stock prediction can not be ignored. 
Therefore, the Bayesian method is proposed in this paper, which embodies the idea: according to the latest news, including the expert experience and subjective judgment, revised historical data model.

\section{REFERENCES}

[1] H. C. John, "The Risk and Return of Ventufe Capital," Tournal of Fimamcics, Vol. 75, No. 1, 2005, pp. 3-52.

[2] Y. Y. Lao, Financial Securities, Beijing. Economic Man- agement Publishing House, 2003.

[3] G. Lee, Financial Economics, Chengdu. Sichuan University press, 1999.

[4] Y. Lu, Financial Market Investment Decision Optimization in Probability Criterion, the Heilongjiang Province Natural Science Fund Project (G0521), 2008.

[5] Y. F. Meng, "Securities Investment," Xiamen. Xiamen University press, 2006

[6] J. Y. Wang, Application of Statistics. Harbin. Heilongjiang People's Publishing House, 1999. 